\title{
Decolorization of different azo dyes by Phanerochaete chrysosporium RP78 under optimal condition
}

\author{
${ }^{1}$ F. Ghasemi; ${ }^{2 *}$ F. Tabandeh; ${ }^{2}$ B. Bambai; ${ }^{3}$ K. R. S. Sambasiva Rao \\ ${ }^{1}$ School of Advanced Medical Technology, Tehran University of Medical Sciences, Tehran, Iran \\ ${ }^{2}$ Department of Industrial and Environmental Biotechnology, National Institute of Genetic Engineering and \\ Biotechnology, Tehran, Iran \\ ${ }^{3}$ Center for Biotechnology, Acharya Nagarjuna University, Nagarjunanagar 522 510, India
}

Received 1 December 2009; $\quad$ revised 10 February 2010; accepted 21 May 2010; availaEOHonline 1 June 2010

\begin{abstract}
Detoxification of synthetic dyes is one of the main challenges in clearing textile industry wastes. Biodegradation of azo-dyes using Phanerochaete chrysosporium is one the most environmentally friendly methods available. The main enzymes responsible for mycodecolorization process are lignin and manganese peroxidases. Here, optimization of expression conditions has been carried out with manipulating culture condition and nutrient sources. Therefore, the effects of buffer and temperature as well as nitrogen source on lignin peroxidase and manganese peroxidase production were investigated at two levels and four levels, respectively. For this purpose, $P$. chrysosporium RP78 based on Taguchi design of experiment has been applied. Maximum lignin and manganese peroxidase activities of $182 \pm 2.5 \mathrm{U} / \mathrm{L}$ and $850 \pm 41 \mathrm{U} / \mathrm{L}$ were obtained under predicted optimum conditions, respectively. Thereby, about $100 \%$ decolorization was achieved after $24 \mathrm{~h}$ for two most widely used groups of azo dyes in textile industry consisting reactive and acidic. The physical adsorption of the azo dyes by mycelia was not significant which indicated that the enzymatic degradation of the dyes was occurred. Time profile of these enzymes showed that manganese peroxidase was peaked on $9^{\text {th }}$ day while lignin peroxidase peaked on $13^{\text {th. }}$ day and remained stable in the culture. The extracellular expression profiles of both were studied by 2 dimensional gel electrophoresis to partially characterize the enzymes.
\end{abstract}

Keywords: Biodegradation; Lignolytic enzymes; Phanerochaete chrysosporium; Taguchi method

\section{INTRODUCTION}

A great variety of synthetic dyes are used for textile dying and other industrial applications. The structural diversity of dyes derives from the use of different chromophoric groups (e.g., azo, anthraquinone, triarylmethan, and phthalocyanine groups) and different application technologies (e.g., reactive, direct, disperse and vat dying) (Heinfling et al., 1998; Bandyopadhyay and Chattopadhyay, 2007). Approximately, 10,000 different dyes and pigments are used industrially and over $7 \times 10^{5}$ tons of these dyes are produced annually worldwide (Spadaro et al., 1992). Physical and chemical technologies for decolorization of textile effluents are very expensive and commercially unattractive (Beydilli et al., 1998). Biodegradation is an alternative to these technologies which is more costeffective, environmentally friendly and do not produce large quantity of sludge (Azmi et al., 1998; Gueu et al.,

凶*Corresponding Author Email: taban_f@nigeb.ac.ir Tel.: +9821 44580359; Fax: +9821 44580399
2007). Azo dyes which are used extensively in many industries are the largest class of synthetic dyes with a wide variety of color and structure (Minussi et al., 2001; Samarghandi et al., 2007; Gharbani et al., 2008). Most of these compounds are highly resistant to microbial attack and therefore they are hardly removed from effluents by conventional biological wastewater treatments, such as activated sludge (Cripps et al., 1990; Heinfling et al., 1998; Igbinosa and Okoh, 2009). The lignin-degrading white rot fungus $P$. chrysosporium mineralizes a wide variety of priority aromatic pollutants (Spadaro et al., 1992; Heinfling et al., 1998; Yadav et al., 2006; Okafor and Opuene, 2007). This microorganism produces various isoforms of extracellular oxidases and peroxidases, which are involved in the degradation of lignin in their natural lignocellulosic substrates (Sato et al., 2007). The first lignolytic peroxidases were isolated from $P$. chrysosporium and called as lignin peroxidase (LiP) 
and manganese peroxidase (Heinfling et al., 1998). Many studies were performed on the production of lignolytic enzymes by $P$. chrysosporium because of the dependence of this enzymatic system on nutrient conditions (Dosoretz et al., 1993; Naidu et al., 2003; Ambrósio and Campos-Takaki, 2004; Sato et al., 2007). Time profiles of these enzymes under different conditions were studied to find the time corresponding to the maximum enzyme activities which is different from one fungus to another (Dosoretz and Grethlein, 1991; Dosoretz et al., 1993). The expression profile of extracellular proteins from $P$. chrysosporium growing on solid and liquid substrates has been recently analyzed by two-dimensional gel electrophoresis (Sato et al., 2007).

Statistical methods of design of experiments are known by DOE as useful tools help to gain more information about the optimum conditions in a few trials (Montgomery, 2001). Among all DOE methods, Taguchi method, a kind of fractional factorial design, involves establishment of large number of experimental situations described as orthogonal arrays to reduce experimental errors and to enhance their efficiency and reproducibility of the laboratory experiments (Krishna Prasad et al., 2005). The effect of the culture conditions consisting $\mathrm{O}_{2}$ and nitrogen and carbon source limitations on the regulation of $\mathrm{LiP}$ and $\mathrm{MnP}$ was studied (Dosoretz and Grethlein, 1991). However, there are no reports available on the application of Taguchi method to investigate the effect of culture parameters on lignolytic enzymes in the field of biodecolorization.

In the present study, an attempt has been made to obtain the culture conditions in which the $P$. chrysosporium showed the highest LiP activity in order to degrade seven azo dyes from four different groups. The experiments were designed based on Taguchi method. Furthermore the expression profile of two main peroxidases, $\mathrm{LiP}$ and $\mathrm{MnP}$ during the decolorization of reactive orange 16 has also been investigated.

\section{MATERIALS AND METHODS}

Chemicals

All chemicals used were of analytical grade and purchased from Sigma and Merck Company and dyes were obtained from Sigma-Aldrich Company.

\section{Microorganism and culture maintenance}

The microorganism Phanerochaete chrysosporium RP78 was obtained from Forest Products Laboratory,
Madison, WI, USA through Center for Biotechnology, Acharya Nagarjuna University, India and was maintained on potato dextrose agar at $30{ }^{\circ} \mathrm{C}$. Subcultures were routinely made every 30 days.

\section{Preparation of spore inoculum}

Spore production required 6 days growth on the PDA medium. Spores were prepared by suspension in sterile water. The spores were separated from mycelia by centrifuging at $5000 \mathrm{~g}$ for $5 \mathrm{~min}$. Spore concentration was determined by measuring absorbance at $650 \mathrm{~nm}$ (an absorbance of $1.0 / \mathrm{cm}$ is approximately $5 \times 10^{6}$ spores/mL) by spectrophotometer (Beckman DU530, USA).

\section{Medium and optimization methodology}

According to Taguchi's orthogonal array L8, eight experiments were used to evaluate the effect of three variables on the production of the lignolytic enzymes (Table 1). The decision on the levels of these components was based on literature data. The factors and their levels were as follows: temperature $\left(30^{\circ} \mathrm{C}\right.$, $37^{\circ} \mathrm{C}$ ), buffer (acetate and sodium succinate, $20 \mathrm{mM}$ ), and ammonium tartrate as nitrogen source (1.2, 12, 24 and $48 \mathrm{mM})$. The composition of the medium was varied according to the experimental plan. The constant constituents of the medium consisted of $56 \mathrm{mM}$ glucose, $1.5 \mathrm{mM}$ veratryl alcohol and mineral salts and $1 \mathrm{mg} / \mathrm{L}$ thiamin at $\mathrm{pH} 4.5$ as described previously (Tien and Kirk, 1988). Stationary liquid cultures were established by inoculating the $20 \mathrm{~mL}$ media with $0.1 \mathrm{~mL}$ fungal spores with absorbance of 0.5 at $650 \mathrm{~nm}$. The cultures were prepared in 250-mL flask equipped with inlet and outlet and flushed with pure oxygen at the time of inoculation and then every three days (Tien and Kirk, 1988).

\section{Biodegradation tests}

The optimized cultures of $P$. chrysosporium were allowed to grow for 8 days at $30^{\circ} \mathrm{C}$. On day 8 , one of the dyes was added to each culture. The dye stock solutions were prepared in distilled water at $0.5 \mathrm{mg} / \mathrm{mL}$ and were added to give final concentration of 40.483, 25.206, 34.736, 62.4, 30.09, 100.5 and $54.182 \mu \mathrm{M}$ for Reactive Orange 16 , Reactive Black 5, Direct Violet 51, Acid Red 88, Acid Red 114, Basic Orange II and Bismarck Brown R, respectively. The final dye concentration of $24 \mathrm{mg} / \mathrm{L}$ was considered for mycodecolorization studies based on the previous data (Naidu et al., 2003; Gao et al., 2006). Dye 
disappearance was detected by spectrophotometer (Beckman DU530, USA) at or near the absorption maximum for each dye at $24 \mathrm{~h}$ intervals for 5 days. Results were reported as the mean values of decolorization percent for three replicates.

\section{Enzymatic assays}

Lignin peroxidase activity was measured according to the method of Tein and Kirk (1988). One unit of activity (U) represents $1 \mu \mathrm{M}$ veratryl alcohol oxidized to the aldehyde per min at room temperature. Manganese peroxidase (MnP) activity was measured by spectrophotometery(Beckman DU530, USA) in presence of $\mathrm{Mn}^{2+}$ as a substrate (Paszczynski et al., 1988)

\section{Electrophoresis}

Equal volumes of extracellular fluid were precipitated with trichloroacetic acid (TCA) and subjected to SDSPAGE (Laemmli, 1970) and also 2D gel electrophoresis as previously described (O’Farrells, 1975). Then the gels were stained with silver nitrate.

\section{RESULTS AND DISCUSSION}

Biodegradation of widely used synthetic dyes in textile industry especially azo ones by $P$. chrysosporium has been investigated previously (Cripps et al., 1990; Goszczynski et al., 1994; Beydilli et al., 1998; Naidu et al., 2003). The lignin degrading system of white-rot fungi is consisted of various extracellular enzymes such as laccases, peroxidases and oxidases (Shah and Nerud, 2002). Therefore, they are able to degrade a wide range of organic pollutants e.g. phenolic compounds and synthetic dyes (Leatham et al., 1983; Cripps et al., 1990; Minussi et al., 2001). The ability of $P$. chrysosporium to degrade a lot of synthetic dyes has been reported (Shah and Nerud, 2002). This is because, this white-rot fungus is able to produce a family of extracellular glycosylated heme-containing lignin peroxidases. These ligninase isoenzymes are highly homologous, with molecular weight ranging from 38-46 KDa and Pi ranging from 3.34.9 (Chaudhry, 1994). Expression of lignolytic enzymes by $P$. chrysosporium is idiophathic, occurs under nitrogen, carbon or sulfur limitation and is particularly active at high $\mathrm{O}_{2}$ tension (Dosoretz et al., 1993). LiP was considered as the main component among these enzymes and the effect of nitrogen limitation on its production was investigated. Furthermore, LiP synthesis under different temperatures with two buffers was simultaneously studied using Taguchi experimantal design. The obtained data from eight Taguchi trials were analyzed using Design Expert software (version 6.0.10, Stat-Ease Inc., USA) for LiP activity as response (Table $1)$. From the calculated ratios $(F)$, it can be referred that the factors considered in the experimental design are statistically significant at $95 \%$ confidence limit. The results showed that all three factors (ammonium tartrate concentration, temperature and type of buffer) and two interactions were significant (Table 2). The ANOVA of LiP activity has the model $F$-value of 450.17 and Prob $>$ F lower than 0.05 that implies it is significant and can be used to navigate in the design space. The model also indicated that the multiple correlation coefficient of $R^{2}$ is 0.999 i.e. it can explain $99 \%$ variation in the response. Furthermore, the predicted $R^{2}$ of 0.975 is in reasonable agreement with the adjusted $R^{2}$ of 0.997 . The model shows standard deviation, mean, C.V. and predicted residual sum of square values of $2.85,52.75$, 5.40 and 463.93, respectively. The software proposed the following equations for prediction and description of the responses according to the actual values of the factors.

Eq. 1 while succinate was as buffer:

LiPActivity $=-287.974-4.906 \times \mathrm{A}+14.179 \times \mathrm{B}$

Eq. 2 while acetate was as buffer:

Table 1: The factors and their levels according to L8 Taguchi orthogonal array

\begin{tabular}{|c|c|c|c|c|}
\hline $\begin{array}{l}\text { Trial } \\
\text { No. }\end{array}$ & $\begin{array}{c}\text { A: } \\
\text { nitrogen source }(\mathrm{mM})\end{array}$ & $\begin{array}{c}\text { B: } \\
\text { Temp }\left({ }^{\circ} \mathrm{C}\right)\end{array}$ & $\begin{array}{c}\text { C: } \\
\text { buffer }\end{array}$ & $\begin{array}{l}\text { LiP activity } \\
\text { U/L }\end{array}$ \\
\hline 1 & 1.2 & 30 & succinate & $3.9 \pm 129.0$ \\
\hline 2 & 1.2 & 37 & acetate & $1.9 \pm 27.0$ \\
\hline 3 & 12.0 & 30 & succinate & $21.0 \pm 81.0$ \\
\hline 4 & 12.0 & 37 & acetate & $11.0 \pm 40.0$ \\
\hline 5 & 24.0 & 30 & acetate & 0.0 \\
\hline 6 & 24.0 & 37 & succinate & $21.0 \pm 120.0$ \\
\hline 7 & 48.0 & 30 & acetate & $13.5 \pm 25.0$ \\
\hline 8 & 48.0 & 37 & succinate & 0.0 \\
\hline
\end{tabular}


Optimization of mycodecolorization of azo dye

Table 2: ANOVA results for Taguchi orthogonal array $L_{8}$

\begin{tabular}{lrccrr}
\hline \multicolumn{1}{c}{ Source } & Sum of squares & DF & Mean Square & F value & Prob. $>$ F \\
\hline Model & 18279.26 & 5 & 3655.85 & 450.17 & 314.00 \\
A & 2550.01 & 1 & 2550.01 & 405.17 & 0.0032 \\
B & 3290.46 & 1 & 3290.46 & 427.18 & 0.0025 \\
C & 3469.19 & 1 & 3469.19 & 761.32 & 38.61 \\
A $\times$ C & 6182.74 & 1 & 6182.74 & 0.0023 \\
B $\times$ C & 313.56 & 1 & 313.56 & 0.0249 \\
Residual & 16.24 & 2 & 8.12 & \\
Cor Total & 18295.50 & 7 & & \\
\hline
\end{tabular}

LiPactivity $=-250.670+1.068 \times \mathrm{A}+7.489 \times \mathrm{B}$

Where, $\mathrm{A}$ is ammonium concentration in the culture medium and $\mathrm{B}$ is temperature.

According to Taguchi analysis the maximum LiP activity of $230 \pm 39 \mathrm{U} / \mathrm{L}$ at the $99 \%$ interval was predicted at $37^{\circ} \mathrm{C}$ in the presence of succinate buffer and $1.2 \mathrm{mM}$ ammonium tartrate (Fig. 1). Therefore, the validation test was carried out in triplicates and LiP activity of $182 \pm 2.5$ $\mathrm{U} / \mathrm{L}$ was achieved.

The effect of initial nitrogen concentration on substrate consumption, LiP and MnP synthesis by $P$. chrysosporium has been studied (Dosoretz et al., 1993). The result indicated that $\mathrm{MnP}$ and then $\mathrm{LiP}$ were appeared in direct response to nitrogen starvation under nitrogen limitation condition, but they were synthesized simultaneously after complete utilization of carbon source under sufficient and excess nitrogen conditions. However the LiP activity was seven times more than the activity observed under nitrogen limitation conditions (Dosoretz et al., 1993). On the other hand, it has been reported that the gradual increase of nitrogen concentration resulted in the decrease of both enzymes (Cripps et al., 1990; Chaudhry, 1994). MnP was active just under the nitrogen limitation condition (trials 1 and 2) and by increasing the nitrogen concentration, its activity completely disappeared. In these two nitrogen limitation conditions (trial 1 and 2); the maximum $\mathrm{MnP}$ activities of $850 \pm 41 \mathrm{UL}$ and $600 \pm 37 \mathrm{U} / \mathrm{L}$ were obtained, respectively. The regression models represent the ammonium concentration has a negative effect on LiP activity while succinate is as buffer. It is in agreement with the previous finding (Cripps et al., 1990; Chaudhry, 1994). As shown in Fig. 1, the higher activity was obtained at higher temperature (from 30 to $37^{\circ} \mathrm{C}$ ) in the presence of each buffer. But the maximum activity was achieved while succinare applied. In literature, both buffers have been applied in lignolytic media (Dosoretz and Grethlein, 1991; Sato et al., 2007). Succinate has two carboxylic groups while acetate has one. The carboxylic group appears to be directly affected by lowering the $\mathrm{pH}$ of the solution. With decreasing $\mathrm{pH}$, redox potential increased and $\mathrm{LiP}$ is able to oxidize its substrate (Oyadomari et al., 2003). The optimum $\mathrm{pH}$ for $\mathrm{LiP}$ activity is 4.2. LiP is stable at $34 \mathrm{U} C$ and $\mathrm{pH} 4.2$ for $100 \mathrm{~h}$ (Couto et al., 2006). Therefore, it seems that succinate buffer is able to supply the optimum $\mathrm{pH}$ for Lip activity and stability rather than acetate buffer.

Daily assay for LiP and MnP under optimal conditions showed that LiP activity was first detected on day 6 and peaked on day 13 as $182 \pm 2.5 \mathrm{U} / \mathrm{L}$. MnP activity was also detected on day 6 and peaked on day 9 up to $850 \pm$ $41 \mathrm{U} / \mathrm{L}$. This pattern of the synthesis of the lignolytic enzymes is in agreement with previous reports under limiting nitrogen conditions (Dosoretz et al., 1993). However, this culture remained lignolytic at least through day 15 (Fig. 2). Therefore, the azo dyes were added on day 8 in which both peroxidases were active in order to investigate their decolorization (Fig. 2). The effective mycodecolorization of 5 azo dyes (acid red 114, acid red 88 , direct violet 51, reactive orange 16 and reactive black 5) related to three groups of azo dyes (acidic, direct and reactive) was observed. In this condition, more than 99 $\%$ of acid red 88, reactive black 5 and reactive orange 16 were degraded in $24 \mathrm{~h}$ while, acid red 114 and direct violet 55 were decolorized after 5 days up to $90 \%$. The mycelia adsorption was measured for the azo dyes of bismarck brown R, acid red 114 and direct violet 51. It was observed that bismarck brown $\mathrm{R}$ was not degraded at all, but adsorbed direct violet 51 and acid red 114 steadily released from mycelia and finally decolorized completely from the culture medium. Some dyes like basic orange II were not decolorized by the lignolytic system of $P$. chrysosporium. The results showed that this strain has a high potential to degrade three groups of azo dyes with one or two azo bonds. It has been reported that disperse and solvent azo dyes are also mineralized by $P$. chrysosporium (Spadaro et al., 1992). The effectiveness of decolorization depends on the 
structure and complexity of synthetic dyes (Minussi et al., 2001; Ambrósio and Campos-Takaki, 2004), e. g. a nitro function may retard the mineralization process (Spadaro et al., 1992). However, decolorization occurs when just the chromophore bond is degraded. The situation and availability of this bond in the dye structure affect the efficiency of decolorization. Generally, the larger molecules with weaker bonds are more frigid. Results also showed that the small molecules with strong bonds (e.g. basic orange II) were not affected efficiently by fungal enzymes.

In the presence of different dyes, the extracellular expression profile was studied by SDS-PAGE gel

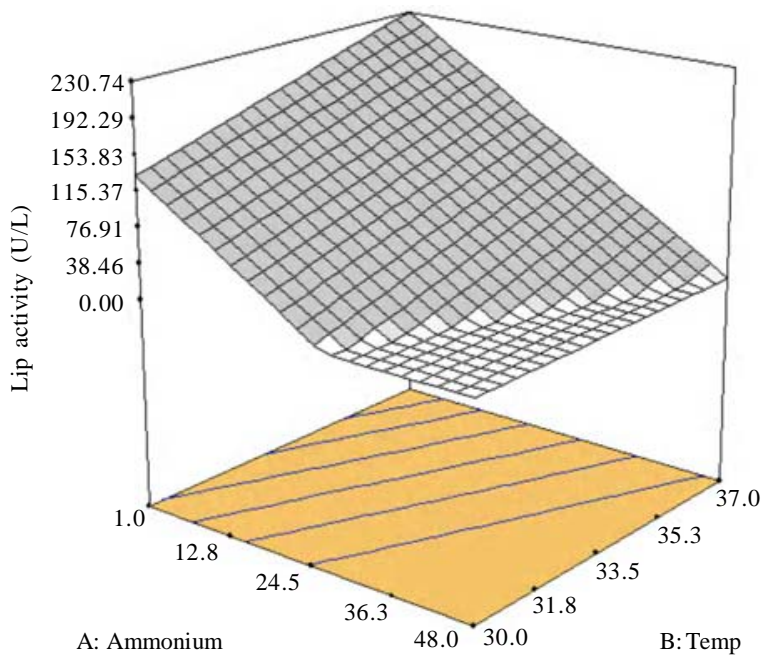

electrophoresis. Fig. 3 showed that there was no significant difference between the patterns of secreted proteins to the culture medium. Three bands were observed in presence and also absence of azo dyes in the medium. It seems that the medium compositions and operational conditions (i.e. no shaking, high aeration) directly affected the expression of lignolytic enzymes.

Two-dimensional gel electrophoresis was employed to characterize the extracellular proteins partially. Three protein spots with MW of 35-45 kDa and pI of 4.2-4.9 were observed in 2D gel electrophoresis (Fig. 4). LiP and MnP activities were also determined and depicted on Fig. 5. Since LiP and

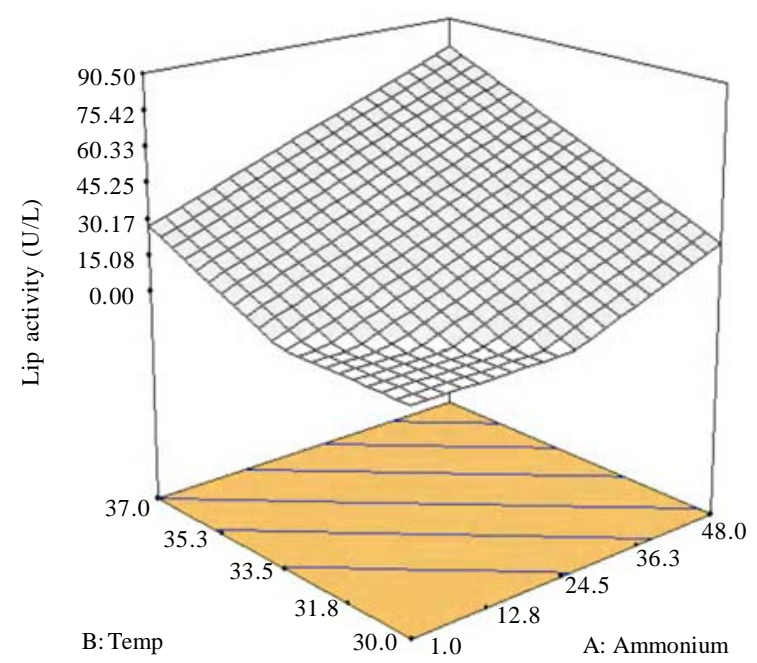

Fig. 1: Three dimensional plan of the LiP activity (U/L) according to different amount of ammonium and temperature in presence of: (i) succinate buffer and (ii) acetate buffer

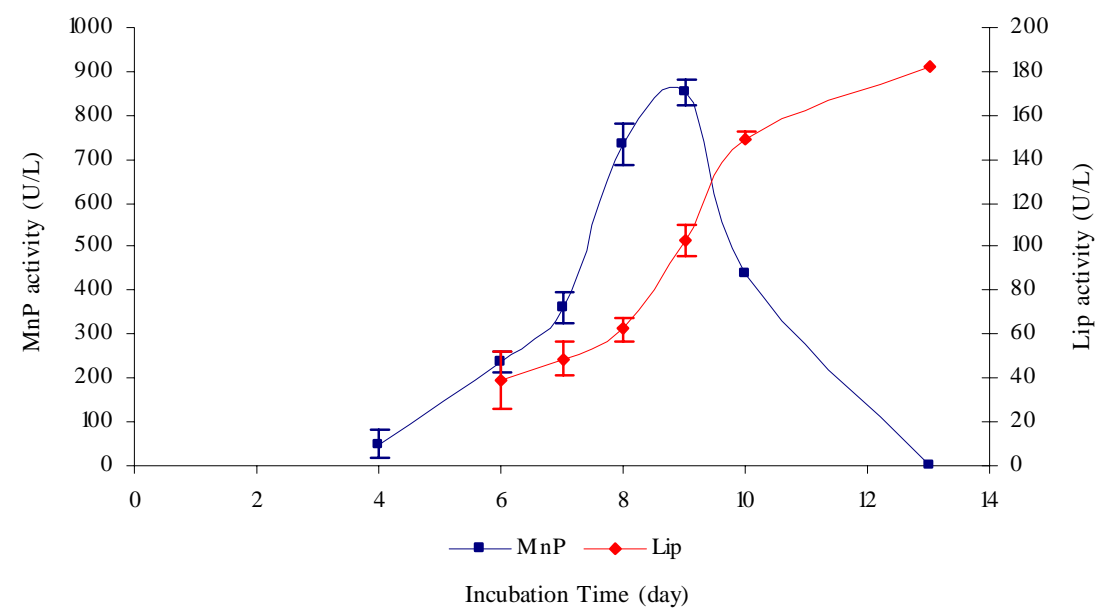

Fig. 2: Time profile of LiP and MnP activities under optimum conditions 


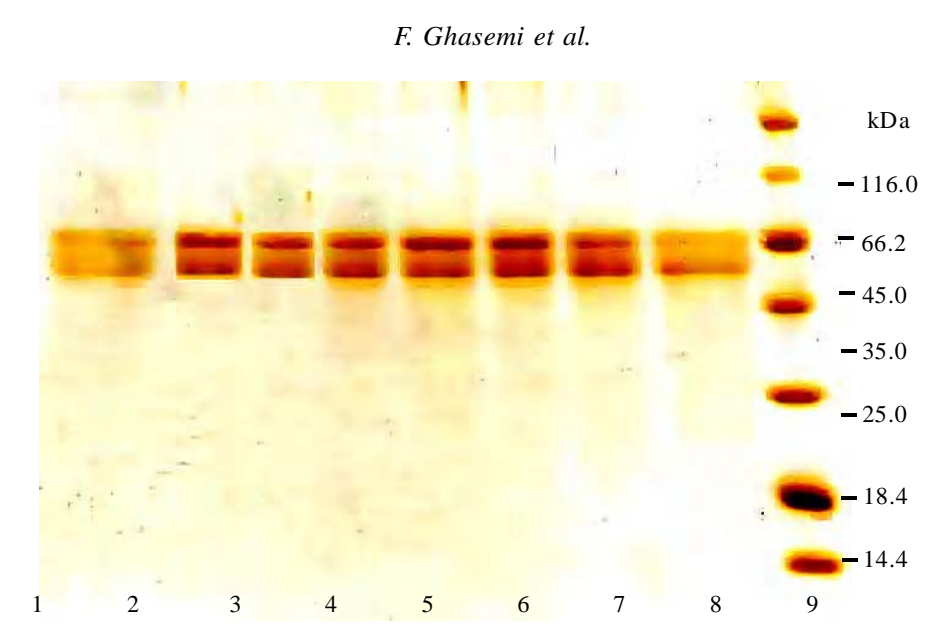

Fig. 3: The extracellular expression profile of the P. chrysosporium RP78 in the presence of different azo dyes after 13 days incubation. Lanes 1: without dye, 2: Reactive Orange 16, 3: Reactive Black 5, 4: Direct Violet 51, 5: Bismarck Brown R, 6: Basic Orange II, 7: Acid Red 114, 8: Acid Red 88, 9: Molecular weight marker

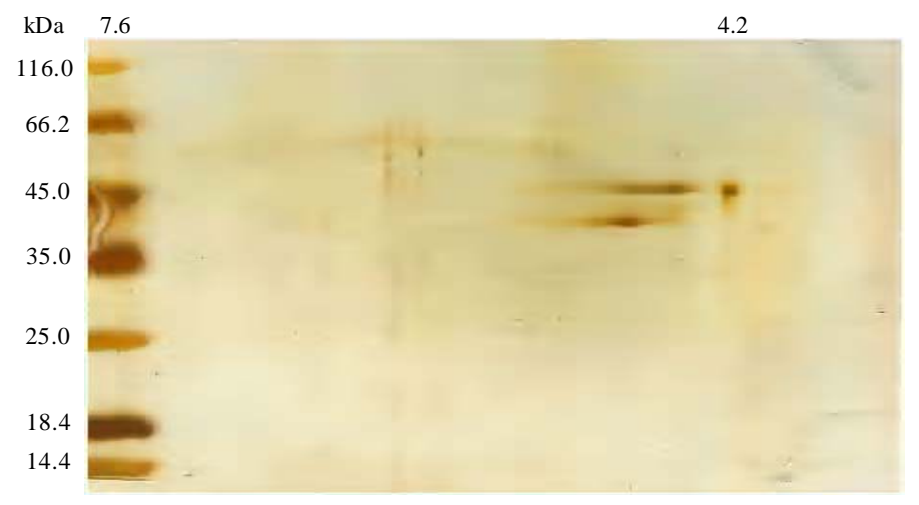

Fig. 4: 2D gel electrophoresis of the extracellular protein expression of the $P$. chrysosporium RP78 under optimal conditions

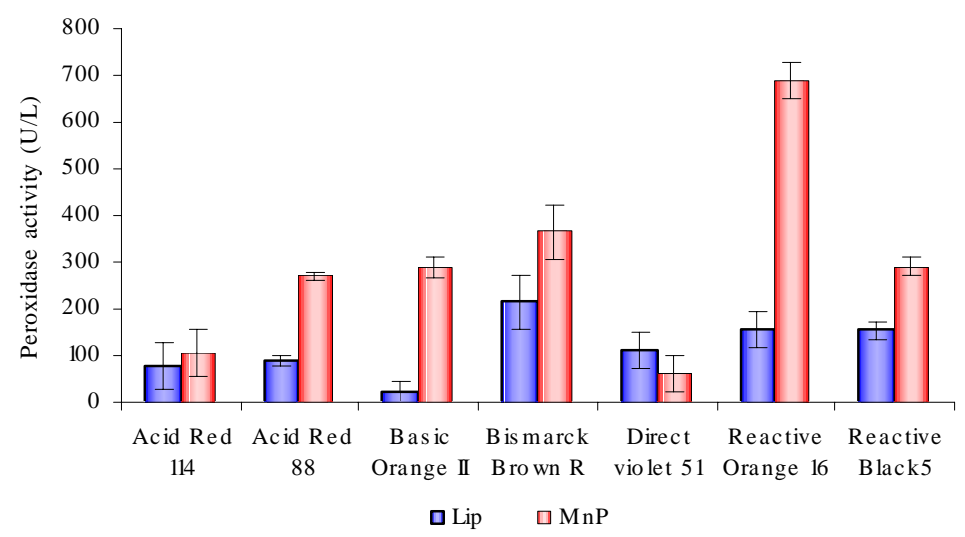

Fig. 5: LiP and MnP activities in the presence of different azo dyes 
MnP activities were assayed quantitatively, the spots are probably related to H1-H5 ligninase isoenzymes according to their molecular weights and isoelecteric pH's. The recent works that had been performed under different substrates and growth conditions had identified different patterns for extracellular proteome of $P$. chrysosporium in different media (Sato et al., 2007).

\section{CONCLUSION}

Effective mycodecolorization of some azo dyes by P. chrysosporium RP78 at the optimum condition has been recorded in the present study. The lignolytic activity was optimized under the nitrogen limitation condition in presence of succinate buffer at $37^{\circ} \mathrm{C}$. It was concluded that the efficiency of dyes decolorization depends on the structure and complexity of azo dyes. The results showed that complex and large structure of these compounds are more sensitive to enzymatic decolorization. Furthermore, the dyes which adsorbed to mycelia required more time for decolorization like Direct Violet 51 and Acid Red 114. SDS-PAGE showed that there is no difference in the extracellular expression pattern in the presence of different azo dyes. Thereupon, it can be concluded that the type of dye has no significant effect on the extracellular enzyme production. Since $P$. chrysosporium RP78 can efficiently decolorize a wide range of textile azo dyes under optimized conditions, further studies on scaling up and using this fungus for treatment of textile waste water are suggested. Meanwhile, this study serves as another example for the application of the Taguchi DOE methodology for improvement of biological process.

\section{ACKNOWLEDGMENTS}

This study was supported by National Institute of Genetic Engineering and Biotechnology (project number 246). The authors also acknowledge Dr. F. Rastegar and Mr. O.M Nourain and Ms. N. Enayatzamir for their great help.

\section{REFERENCES}

Ambrósio, S. T.; Campos-Takaki, G. M., (2004). Decolorization of reactive azo dyes by cunninghamella elegans UCP 542 under co-metabolic conditions. Bioresour. Tech., 91 (1), 69-75 (7 pages).

Azmi, W.; Sani, R. K.; Banerjee, U. C., (1998). Biodegradation of triphenylmethane dyes. Enzyme Microb. Tech., 22 (3), 185-191 (7 pages).
Bandyopadhyay, G.; Chattopadhyay, S., (2007). Single hidden layer artificial neural network models versus multiple linear regression model in forecasting the time series of total ozone. Int. J. Environ. Sci. Tech., 4 (1), 141-150 (10 pages).

Beydilli, M. I.; Pavolsathis, S. G.; Tincher, W. C., (1998). Decolorization and toxicity screening of selected reactive azo dyes under methanogenic condition. Water Sci. Tech., 38 (4-5), 225-232 (8 pages).

Chaudhry, G. R., (1994). Biological degradation and bioremediation of toxic chemicals. $1^{\text {st. }}$ Ed., Chapman and Hall, 345-363 (19 pages).

Couto, S.; Moldes, D.; Sanromán, M., (2006). Optimum stability conditions of $\mathrm{pH}$ and temperature for ligninase and manganese-dependant peroxidase from phanerochaete chrysosporium. Application to in vitro decolorization of poly R-478 by MnP. World J. Microb. Biot., 22 (6), 607612 (6 pages).

Cripps, C.; Bumpus, J. A.; Aust, S. D., (1990). Biodegradation of azo and heterocyclic dyes by phanerochaete chrysosporium. Appl. Environ. Microb., 56 (4) , 11141118 (5 pages).

Dosoretz, C. G.; Grethlein, H. E., (1991). Physiological aspects of regulation of extracellular enzymes of Phanerochaete chrysosporium. Appl. Biochem. Biotech., 28 (29), 253-265 (12 pages).

Dosoretz, C. G.; Rothschild N.; Hard, Y., (1993). Overproduction of lignin peroxidase by phanerochaete chrysosporium (BKM-F-1767) under nonlimiting nutrient condition. Appl. Environ. Microb., 59 (6), 1919-1926 (8 pages).

Gao, D.; Wen, X.; Zhou, X.; Qian, Y., (2006). Effect of trace element on the growth of white rot fungi and suppressing yeast in liquid medium. Environ. Sci., 27 (8), 1623-1626 (5 pages).

Gharbani, P.; Tabatabaii, S. M.; Mehrizad, A., (2008). Removal of Congo red from textile wastewater by ozonation. Int. J. Environ. Sci. Tech., 5 (4), 495-500 (7 pages).

Goszczynski, S.; Paszczynski, A.; Basti-Gorigsby, M. B.; Crawford, R. L.; Crawford, D. L., (1994). New pathway for degradation of sulfonated azo dyes by microbial peroxidases of phanerochaete chrysosporium and Streptomyces chromofuscus. J. Bacteriol., 176 (5), 13391347 (9 pages).

Gueu, S.; Yao, B.; Adouby, K.; Ado, G. (2007). Kinetics and thermodynamics study of lead adsorption on to activated carbons from coconut and seed hull of the palm tree. Int. J. Environ. Sci. Tech., 4 (1), 11-17 (6 pages).

Heinfling, A.; Martinez, M. J.; Martinez, A. T.; Bergbauer, M.; Szewzyk, U., (1998). Transformation of industrial dyes by manganese peroxidase from Bjerkandera adusta and Pleurotus eryngii in a manganese-independent reaction. Appl. Environ. Microb., 64 (8), 2788-2793 (6 pages).

Igbinosa, E. O.; Okoh, A. I., (2009). Impact of discharge wastewater effluents on the physico-chemical qualities of a receiving watershed in a typical rural community. Int. J. Environ. Sci. Tech., 6 (2), 175-182 (8 pages).

Krishna Prasad, K.; Venkata Mohan, S.; Sreenivas Rao, R.; Ranjan Pati, B.; Sarma, P. N., (2005). Laccase production by pleurotus ostreatus 1804: Optimization of submerged culture condition by Taguchi DOE methodology. Biochem. Eng. J., 24 (1), 17-26 (10 pages) 
Laemmli, U., (1970). Cleavage of structural protein during the assembly of the head of bacteriophage T4. Nature, 277 (5259), 680-685 (6 pages).

Leatham, G. F.; Crawford, R. L.; Kirk, T. K., (1983). Degradation of phenolic compounds and ring cleavage of catechol by Phanerochaete chrysosporium. Appl. Environ. Microb., 46 (1) , 191-197 (7 pages).

Minussi, R. C.; de Moraes, S. G.; Pastore, G. M.; Duran, N., (2001). Biodecolorization screening of synthetic dyes by four white-rot fungi in a solid medium: Possible role of siderophores. Lett. Appl. Microb., 33 (1), 21-25 (5 pages).

Montgomery, D. C., (2001) Design and analysis of experiments. $5^{\text {th. }}$ Ed., John Wiley and Sons Inc, New York.

Naidu, K. S. B; Reddy, N. S.; Rao G. V.; Rao, K. R. S. S., (2003). Biodegradation of textile dyes using Phanerochaete chrysosporium. Indian J. Ecol., 30 (1), 268-270 (3 pages).

O'Farrells, P. H., (1975). High resolution two-dimensional electrophoresis of proteins. J. Biol. Chem., 250 (10), 4007 4021 (15 pages).

Okafor, E. Ch.; Opuene, K., (2007). Preliminary assessment of trace metals and polycyclic aromatic hydrocarbons in the sediments. Int. J. Environ. Sci. Tech., 4 (2), 233-240 (9 pages).

Oyadomari, M.; Shinohara, H.; Johjima, T.; Wariishi, H.; Tanaka, H., (2003). Electrochemical characterization of lignin peroxidase from the white-rot basidiomycete Phanerochaete chrysosporium. J. Mol. Catal. B-enzymatic, 21 (4-6), 291-297 (7 pages).
Paszczynski, A.; Crawford, R. L.; Huynh, V., (1988). Manganese peroxidase of phanerochaete chrysosporium: purification. Method. Enzymol., 161 , 264-270 (7 pages).

Samarghandi, M. R.; Nouri, J.; Mesdaghinia, A. R.; Mahvi, A. H.; Nasseri, S.; Vaezi, F., (2007). Efficiency removal of phenol, lead and cadmium by means of UV/TiO2/H2O2 processes. Int. J. Environ. Sci. Tech., 4 (1), 19-25 (7 pages).

Sato, S.; Liu, F.; Koc, H.; Tien, M., (2007). Expression analysis of extracellular protein from Phanerochaete chrysosporium grown on different liquid and solid substrates. Microbiology, 153 (9), 3023-3033 (11 pages).

Shah, V.; Nerud F., (2002). Lignin degrading system of whiterot fungi and its exploitation for dye decolorization. Can. J. Microbl., 48 (10), 857-870 (4 pages).

Spadaro, J. T.; Gold, M. H.; Renganathan, V., (1992). Degradation of azo dyes by the lignin degrading fungus Phanerochaete chrysosporium. Appl. Environ. Microb., 58 (8), 2397-2401 (5 pages).

Tien, M.; Kirk, K., (1988). Lignin peroxidase of Phanerochaete chrysosporium. Method. Enzymol., 161, 238-249 (12 pages).

Yadav, J. S.; Doddapaneni, H.; Subramanian, V., (2006). P450ome of the white-rot fungus phanerochaete chrysosporium: Structure, evolution and regulation of expression of genomic P450 Clusters. Biochem. Soc. T., 34 (6), 1165-1169 (4 pages).

\section{AUTHOR (S) BIOSKETCHES}

Ghasemi, F., Ph.D. Candidate, School of Advanced Medical Technology, Tehran University of Medical Sciences, Tehran, Iran.

Email:fahimeh2005@yahoo.com

Tabandeh, F., Ph.D., Department of Industrial and Environmental Biotechnology, National Institute of Genetic Engineering and Biotechnology, Tehran, Iran. Email: taban_f@nigeb.ac.ir

Bambai, B., Ph.D., Department of Industrial and Environmental Biotechnology, National Institute of Genetic Engineering and Biotechnology, Tehran, Iran. Email: bambai@nigeb.ac.ir

Sambasiva Rao, K. R. S., Ph.D., Full Professor and Head of Center for Biotechnology, Acharya Nagarjuna University, Nagarjunanagar 522 510, India. Email: krssrao@yahoo.com

How to cite this article: (Harvard style)

Ghasemi, F.; Tabandeh, F.; Bambai, B.; Sambasiva Rao, K. R. S., (2010). Decolorization of different azo dyes by Phanerochaete chrysosporium RP78 under optimal condition. Int. J. Environ. Sci. Tech., 7 (3), 457-464. 